\section{Drug-induced small-bowel mucosal atrophy}
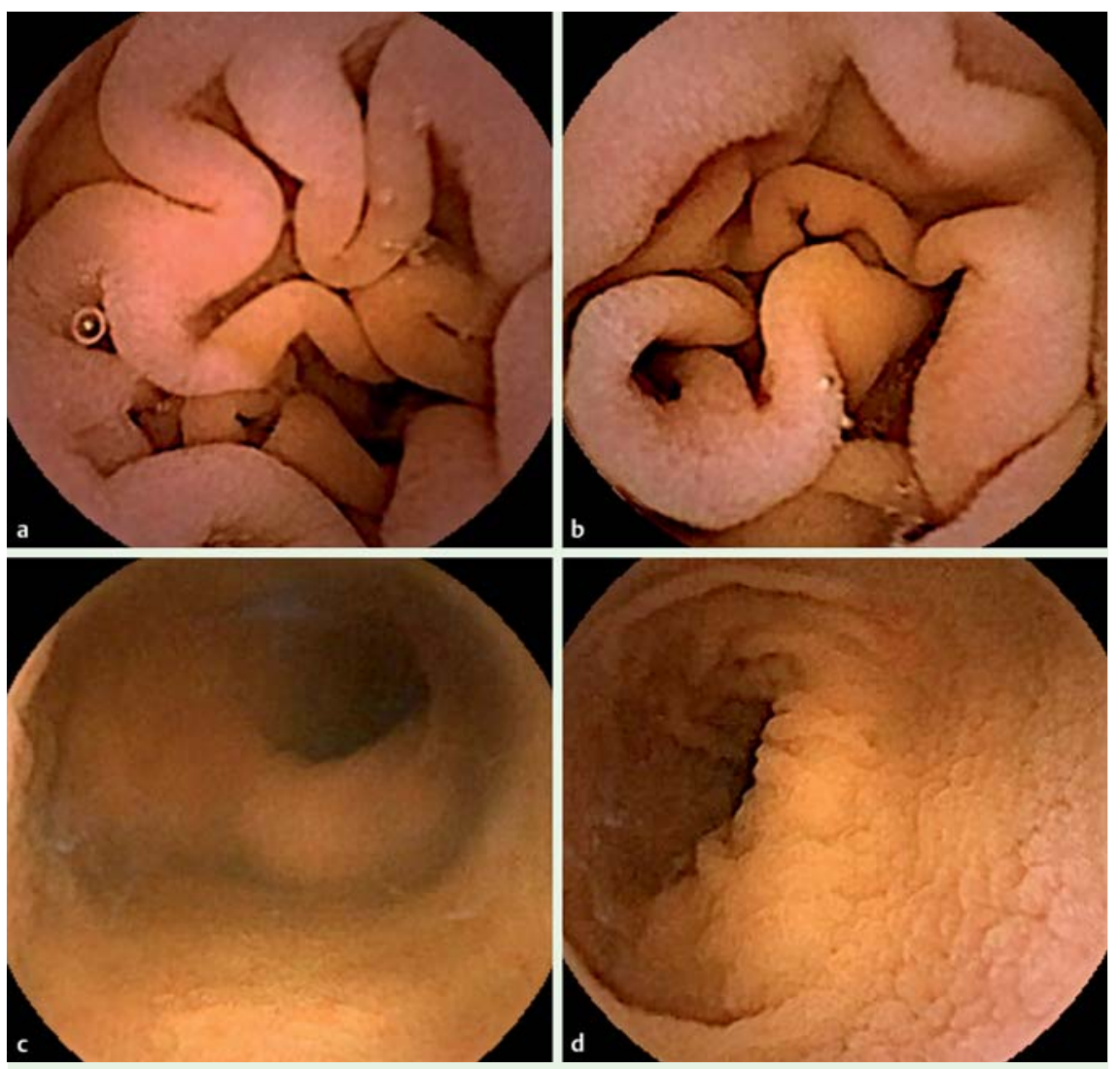

Fig. 1 Image of drug-induced small-bowel mucosal atrophy recorded during capsule endoscopy.

A 65-year-old man being treated with olmesartan for arterial hypertension was admitted because of chronic diarrhea and marked weight loss of about $15 \mathrm{~kg}$ during the past year. He had no fever or abdominal pain. He had not traveled recently to other countries and had no domestic pets. Blood tests showed normocytic anemia $(11.9 \mathrm{~g} / \mathrm{dL})$ and hypoalbuminemia $(30.4 \mathrm{~g} / \mathrm{L})$. The leukocyte count, C-reactive protein level, and liver chemistries were normal. Serology for celiac disease was negative, the thyroid hormone levels were normal, the autoimmune study and immunoglobulin levels were normal, and the results of stool analysis (Clostridium, virology, bacteriology, mycobacteriology, and parasitology) were negative. Abdominal computed tomography was unremarkable, showing no evidence of pancreatic disease. Upper gastrointestinal endoscopy showed a paucity of duodenal folds, and the colonoscopy findings were normal. Capsule enteroscopy showed smooth mucosa in the duodenum and jejunum ( $\bullet$ Fig. $1 \mathbf{a}-\mathbf{d}$ ), with areas of total loss of villi. Duodenal and jejunal biopsies negative results of an immunohistochemistry study for celiac disease and negativity for amyloid, granulomas, microorganisms, and malignancy.

Because of the negative results of an extensive work-up and the relapsing nature showed unspecific mucosal atrophy, with of the patient's symptoms, which were simultaneous with long periods of drug intake, his diarrhea was attributed to the olmesartan. The drug was discontinued, and the patient progressively recovered during the following weeks, with a return to his normal weight and blood values and with no further relapses after 1 year of drug withdrawal.

Olmesartan-induced enteropathy is a newly described entity, with nearly 50 cases in the literature recently reviewed [1]. However, capsule enteroscopy images of this unique form of small-bowel atrophy have not been previously published.

Endoscopy_UCTN_Code_CCL_1AC_2AH

\section{Competing interests: None}

\section{João Santos-Antunes ${ }^{1,2}$, Rosa Coelho', Hélder Cardoso ${ }^{1}$, Guilherme Macedo ${ }^{1}$}

${ }^{1}$ Department of Gastroenterology, Faculty of Medicine, Centro Hospitalar São João, Porto, Portugal

2 Department of Biochemistry, Faculty of Medicine, University of Porto, Portugal

\section{Reference}

1 Ianiro G, Bibbò S, Montalto M et al. Systematic review: sprue-like enteropathy associated with olmesartan. Aliment Pharmacol Ther 2014; 40: 16-23

\section{Bibliography}

DOI http://dx.doi.org/

10.1055/s-0034-1377984

Endoscopy 2015; 47: E8

(c) Georg Thieme Verlag KG

Stuttgart · New York

ISSN 0013-726X

\section{Corresponding author}

\section{João Santos-Antunes, MD}

Department of Gastroenterology,

Hospital de São João

Biochemistry Department, Faculty of Medicine,

University of Porto

Alameda Professor Hernâni Monteiro

4200-319 Porto

Portugal

Fax: +351-22-502-5766

joao.claudio.antunes@gmail.com 